\title{
Formulation and characterization of alprazolam transdermal gel based on nanoliposomes
}

\author{
Seyed Hesamoddin Hashemi ${ }^{1}$, Majid Montazer ${ }^{2}$, Nasser Naghdi ${ }^{3}$, Tayebeh Toliyat ${ }^{4}$ \\ ${ }^{I}$ PhD Student, Department of Textile Engineering, Science and Research Branch, Islamic Azad University, Tehran, Iran \\ ${ }^{2}$ Professor, Department of Textile Engineering, Amirkabir University of Technology, Tehran, Iran \\ ${ }^{3}$ Professor, Department of Physiology and Pharmacology, Pasteur Institute of Iran, Tehran, Iran \\ ${ }^{4}$ Associate Professor, Department of Pharmaceutics, Tehran University of Medical Sciences, Tehran, Iran
}

\begin{abstract}
Background: Nowadays transdermal drug delivery systems (TDDS), as an appropriate replacement for oral and parenteral dosage forms, are developing. These systems which designed to transport drugs through skin layers into the systemic circulation, have several benefits such as avoiding first-pass metabolism, sustained and controlled drug release, reducing side effects, and ease of use. The aim of this study was to formulate alprazolam transdermal gel, as a short-acting anxiolytic of benzodiazepines class, based on the nanoliposomes.

Materials and methods: At the first, different amounts of phospholipid, and cholesterol were used to produce alprazolam-loaded nanoliposomes through solvent injection method. Vesicle size and encapsulation efficiency tests were performed on the samples and statistical models based on response surface methodology (RSM) were developed to find the optimal formulation. Optimal liposomal structure after morphological characterization was used to produce alprazolam $0.5 \mathrm{mg} / \mathrm{g}$ transdermal gel. Three formulated gels with different content of carbomer were examined for viscosity, stability and in vitro skin permeation.

Results: The optimal formulation of the liposomal structure included $10 \mathrm{mg} / \mathrm{mL}$ of phospholipid and $10 \%$ $\mathrm{w} / \mathrm{w}$ cholesterol, resulted in the production of nanoliposomes with a size of $115 \mathrm{~nm}$ and an encapsulation efficiency of $91 \%$. As the carbomer content in the gel increased, the rate of drug permeation into the skin was decreased.

Conclusion: Alprazolam transdermal gel was successfully formulated in this research with acceptable skin permeation, good stability and appropriate physicochemical characteristics.

Keywords: Transdermal gel, Alprazolam, Nanoliposomes, Methanol injection method, Response surface methodology (RSM).

Cited as: Hashemi SH, Montazer M, Naghdi N, Toliyat T. Formulation and characterization of alprazolam transdermal gel based on nanoliposomes. Medical Science Journal of Islamic Azad University, Tehran Medical Branch 2020; 30(4): 376-386.

Correspondence to: Majid Montazer

Tel: +982164542657

E-mail: tex5mm@aut.ac.ir

ORCID ID: 0000-0001-7846-0128

Received: 26 Jun 2020; Accepted: 4 Nov 2020
\end{abstract}


مجله علوم يزشكى دانشخاه آزاد اسلامى

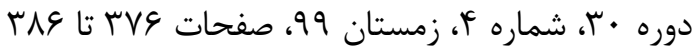

Original

Article

\section{فرمولاسيون و بررسى خصوصيات زل ترايوستى آليرازولام بر پايه نانولييوزوم}

\section{سيدحسام الدين هاشمى'، مجيد منتظر ‘، ناصر نقدى ‘ّ طيبه توليت}

' دانشجوى دكترى تخصصى، كروه مهيندسى نساجى، واحد علوم و تحقيقات، دانشكاه آزاد اسلامى، تهران، ايران

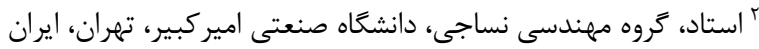

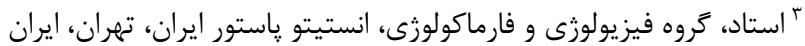

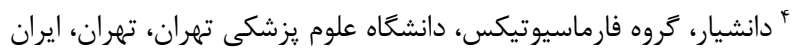

جكيده

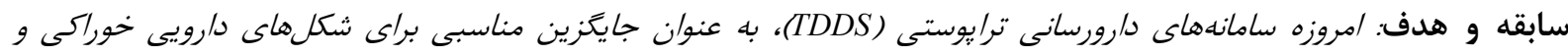

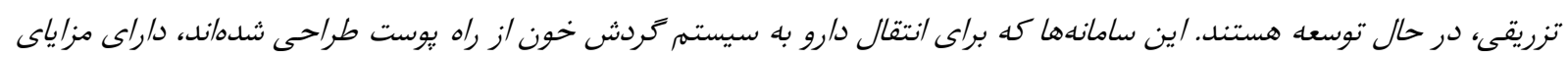

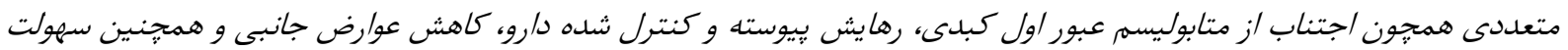

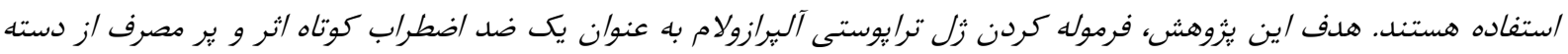

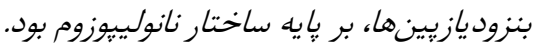

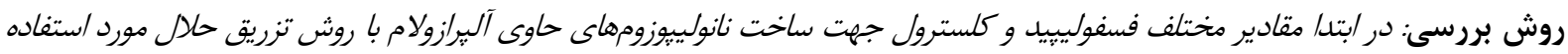

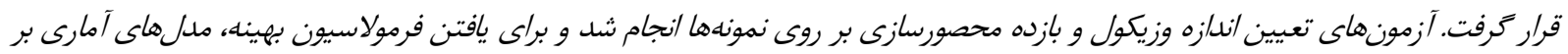

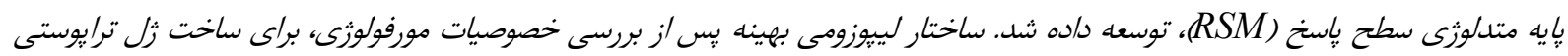

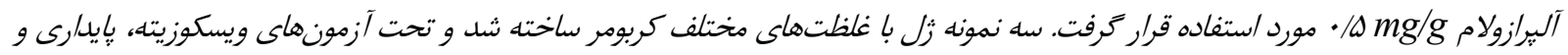

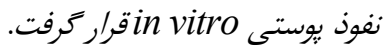

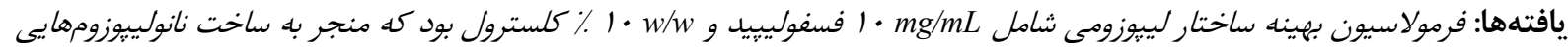

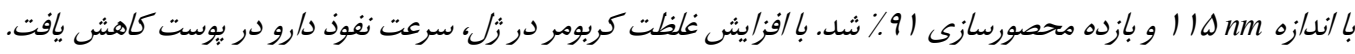

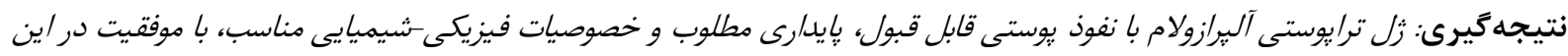

وازگكان كليدى: زل ترايوستى، آلبرازولام، نانوليبوزوم، روش تزريق حلال، متدلوزى سطح باسخ.

كردش خون از طريق يوست، توسعه يافتهاند. اين سامانهها از

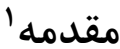

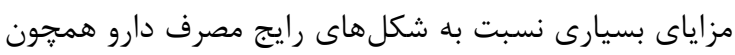
روشهاى خوراكى و تزريقى، برخوردارند. از جمله مزاياى اين

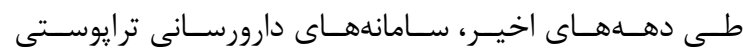

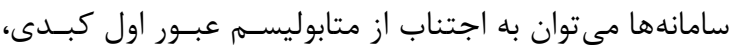

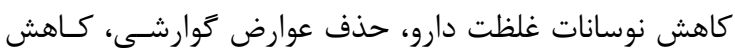
بـراى (Transdermal Drug Delivery Systems: TDDS) عوارض جانبى، سهولت مصرف، سـاز كارى و انطبـاق بهتــر بـا

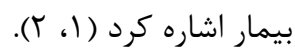$$
\text { انتقال طيف وسيعى از مولكولهاى دارويى فعال بـه سيسـتم }
$$ 


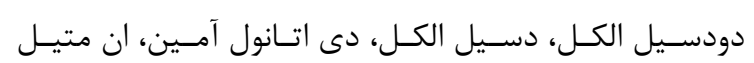

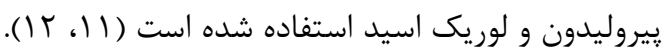

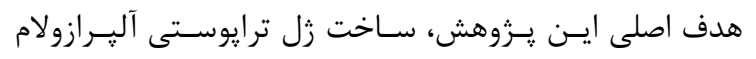

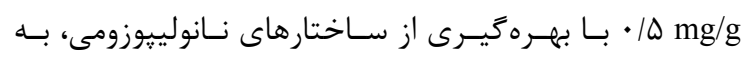

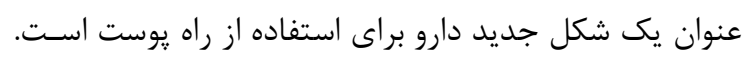

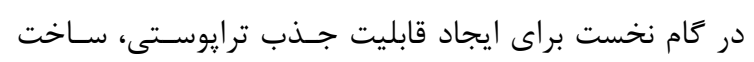

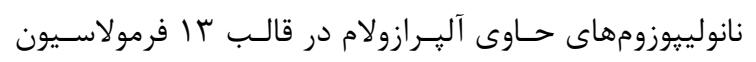

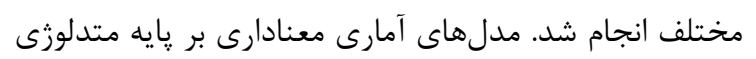

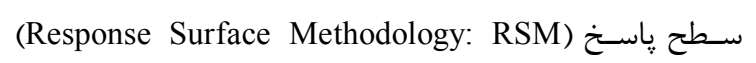
براى اندازه لييوزوم و بازده محصورسازى نمونهها، بــهـ عنــان

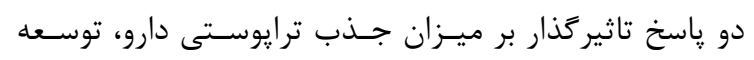

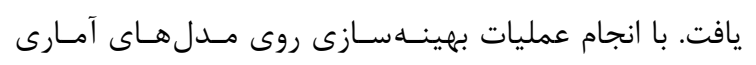

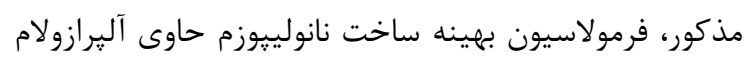

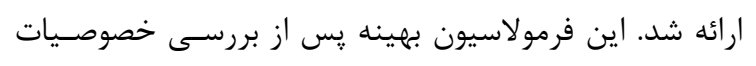

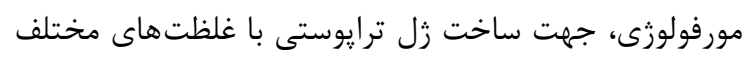

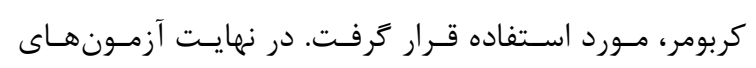

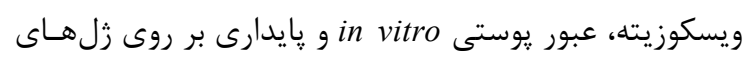
ترايوستى آلِرازولام انجام شد.

\section{مواد و روشها - (- مواد \\ مواد}

آليرازولام با درجه خلوص 99/9 ٪ محصـول شـركت دارويسى

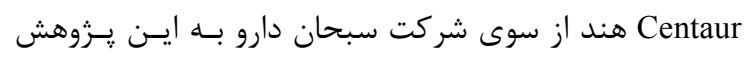

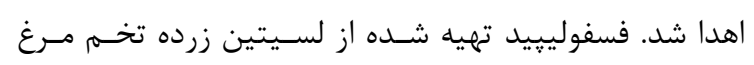

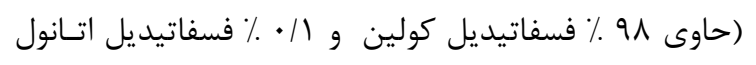

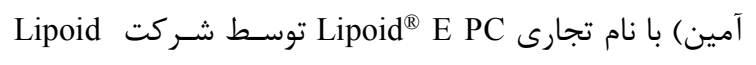

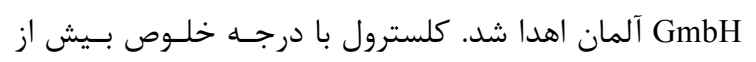

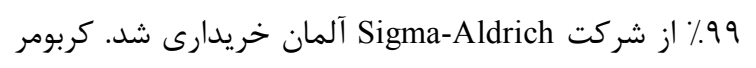

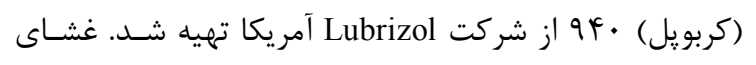

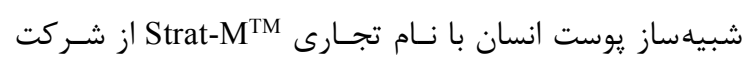
Merck Millipore

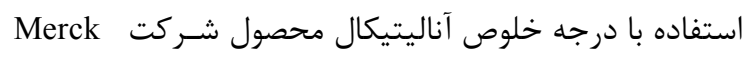

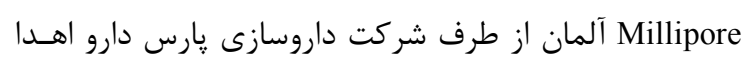

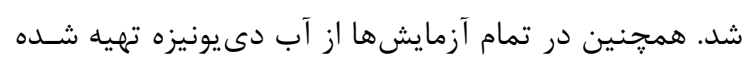

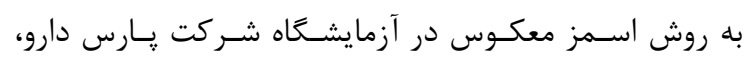
استفاده شد.

\section{ساخت نانولييوزوم حاوى آليرازولام}

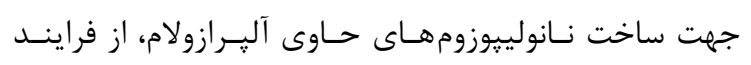

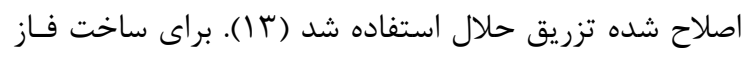

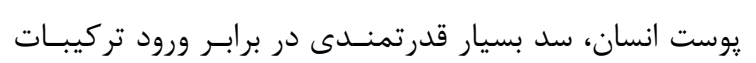

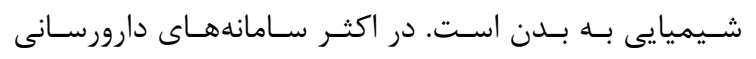

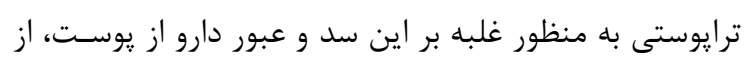

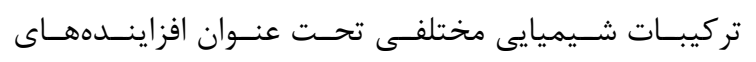

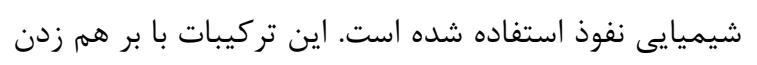

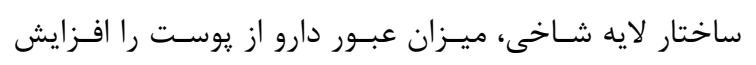

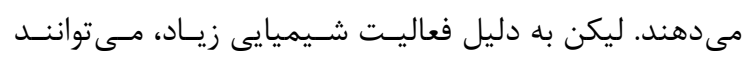

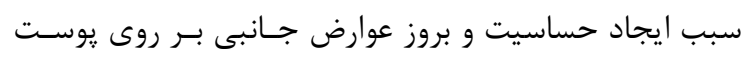

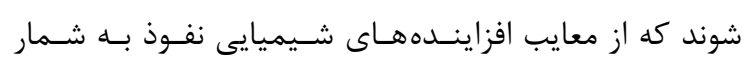

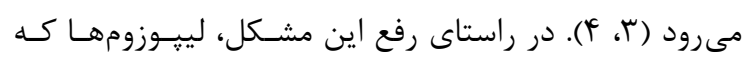

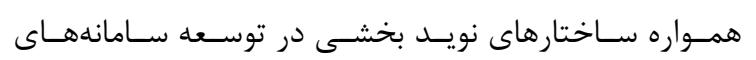

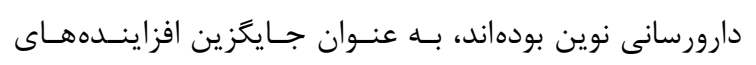

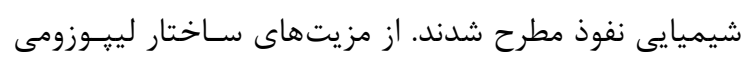

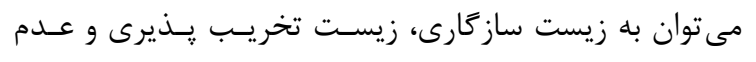
ايجاد حساسيت و عوارض يوستى اشاره كرد ( ا، ه).

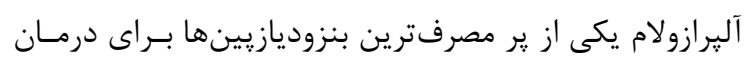

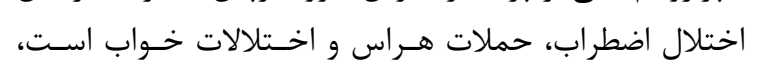

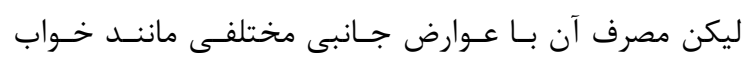

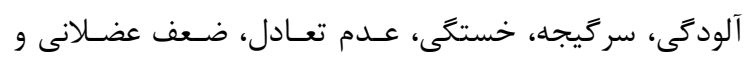

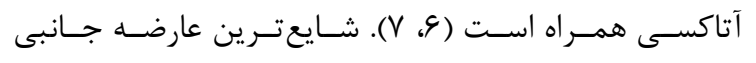

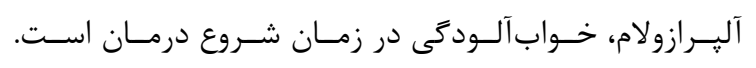

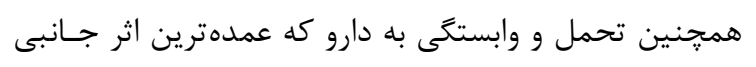

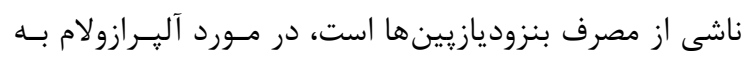

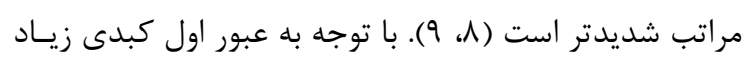

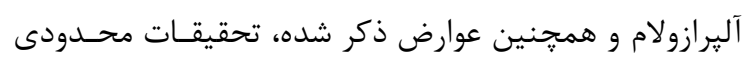

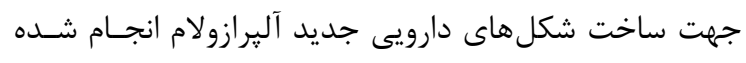

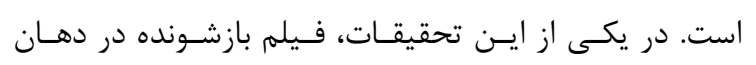

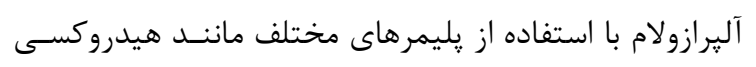

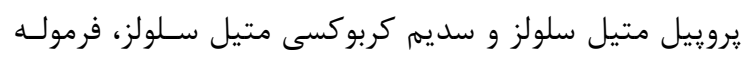

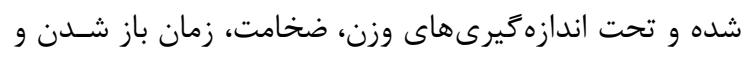

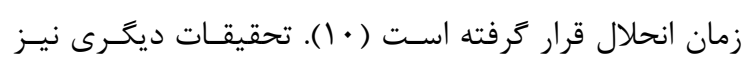

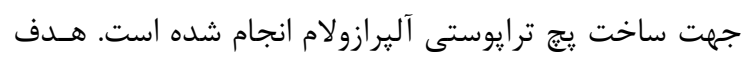

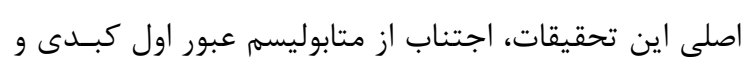

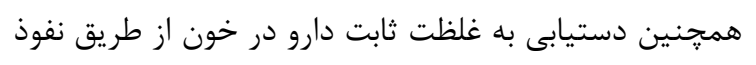

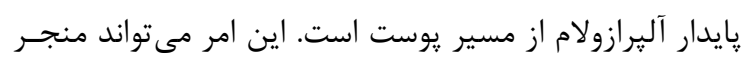

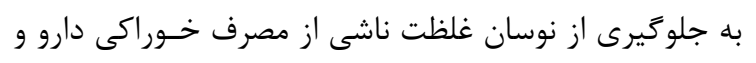

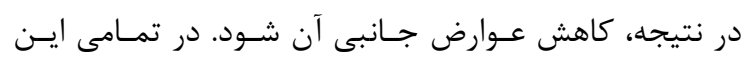

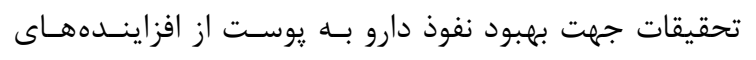

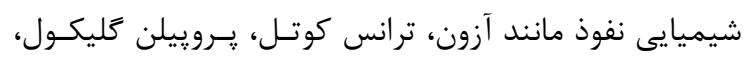




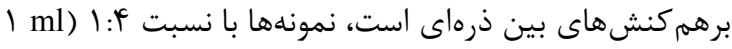

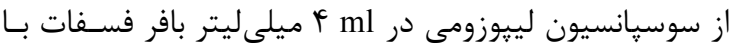

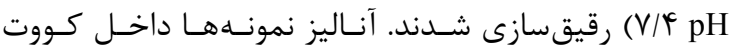
"يلاستيكى و در دماى له درجه سانتى گراد صورت يذيرفت و براى هر نمونه ب مرتبه تكرار شد. نتايج به صورت ميانگين انحراف معيار در جدول ا زَزارش شده است.

\section{تعيين بازده محصورسازى}

بــهـ منظــور تعيــين مقــدار آليــرازولام محصــور شـــده در نانولييوزومها (Ealprazolam) از تكنيك اولتراسانتريفيوز استفاده شد (ها ). بازده محصورسازى عبارت اسـت از نسـبت مقـدار آليرازولام محصور شده در نانوليتوزومها (Ealprazolam) به مقدار كل آليرازولام در سوسيانسيون (Talprazolam) كه توسط فرمول

ا محاسبه شد.

(فرمول () (ف) (1)

$$
E E \%=\frac{E_{\text {alprazlam }}}{T_{\text {alpranolam }}} \times 100
$$

در ابتدا حجم برابرى از نمونههاى سوسيانسيون ليبوزومى به منظور جداسازى و حذف داروى بارگذارى نشده، به مدت • ب

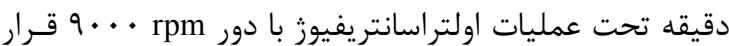

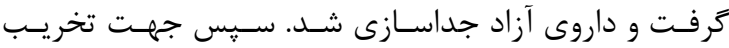
ساختارهاى لييوزومى و خروج داروى محصـور شـده، بـه هـر

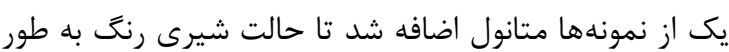
كامل از بين رفته و نمونه شفاف شود. حجـهم متـانول اضـافه شده به هر نمونه در اين مرحله ثبت و در محاسـبات تعيـين مقدار لحاظ شد. در نهايت با روش HPLC مقـدار آليــرازولام خارج شده از ساختارهاى لييوزومى، تعيين شد. جهت تعيين مقدار كـل آليــرازولام (Talprazolam) در سوسيانسـيون، حجـم لم

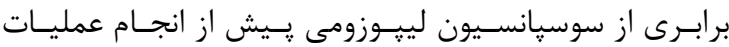

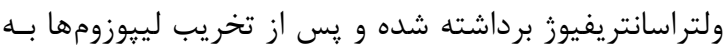
واسطه افزودن متانول مطابق با رويه مرحله قبل، توسط روش

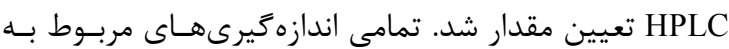

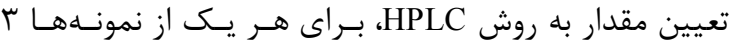

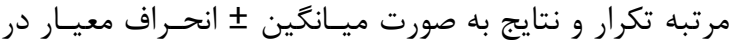
جدول ا ززارش شده است.

آزمون تعيين مقدار آليرازولام

روش مندرج در فارماكويه آمريكا (منوگراف آليرازولام) جهت

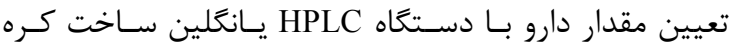
جنوبى، مورد استفاده قرار گرفت. دستخاه مجهز به آشكارساز فرابنفش بود و تجزيه و تحليل دادهها توسط نرمافزار Clarity صورت يذيرفت.
آلـى، mg • • آليــرازولام همـــراه بــا مقــادير تعيـيـن شــده فسفوليييد و كلسترول براى هر فرمولاسيون مطابق با جـدول

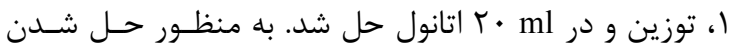
بهتر اجزاء داخل اتانول، از حمام اولتراسونيك به مـدت يـك لهـ

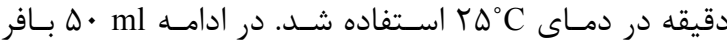

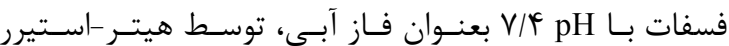

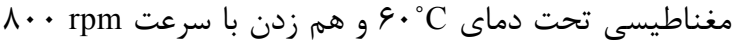

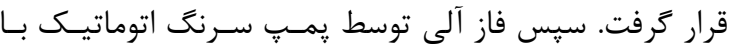

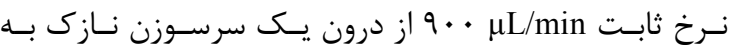
قسمت ميانى فاز آبى تزريق شـد. يـس از خاتمـهـ تزريـق بــه منظور حذف اتانول باقيمانده از طريق تبخيـر، سوسيانسـيون

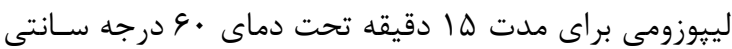

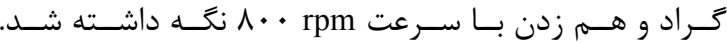

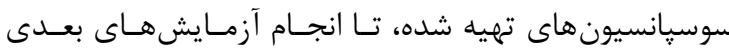
داخل يخجال و در دماى \& درجه سانتى گراد نگَهدارى شد. طراحى آزمايشات ساخت نانولييوزوم حاوى آليرازولام به منظـور يـافتن ارتبـاط ميـان يارامترهـاى فرمولاسـيون و

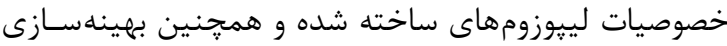
فرمولاسيون لييوزومى، از دو تكنيكى سـطح پاســخ (RSM) و طرح مركسب مركـىى (Central Composite Design: CCD)

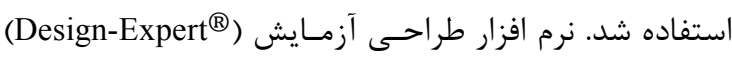

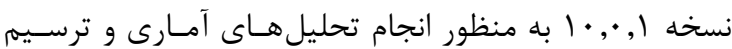

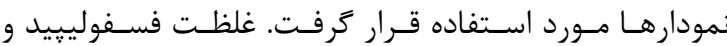
محتواى كلسترول، به عنوان دو فاكتور مـوثر بـر خصوصـيات

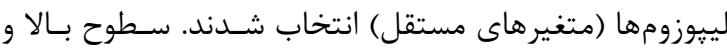
پايين فاكتورها بر گايه نتايج تحقيقات قبلى تعيين شد. اندازه وزيكول و بازده محصورسازى به عنوان مهممترين خصوصـيات

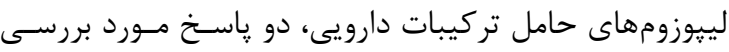

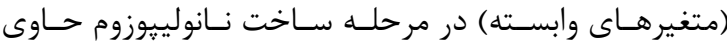

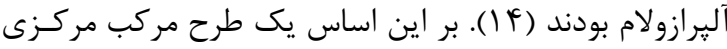
مشتمل بر دو فاكتور در ينج سطح، به منظور غربـالكرى اثـر اصلى فاكتورهاى مورد بررسى روى دو ياسخ اندازه وزيكول و بازده محصورسازى، مطابق با جدول ا طراحى شد. تعيين اندازه وزيكول

متوسط و توزيع اندازه وزيكول در نمونسهـهـا توسـط تكنيـك

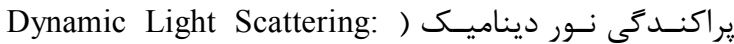
Malvern و با استفاده از دستخاه سنجش اندازه ذرات (DLS

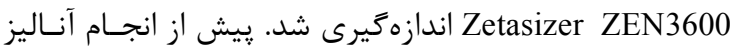

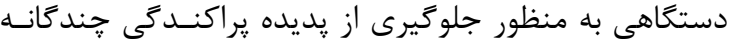
(Multiple Scattering Phenomena) 


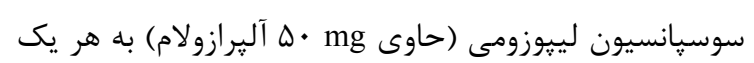

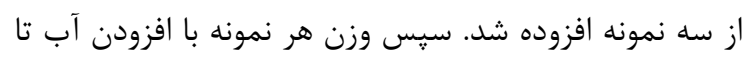

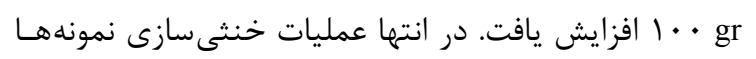

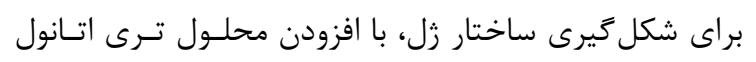

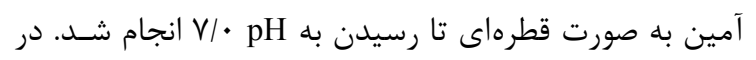

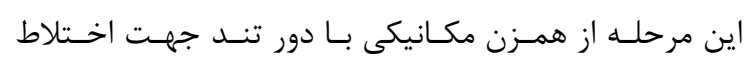

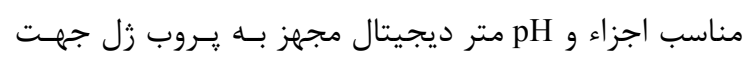

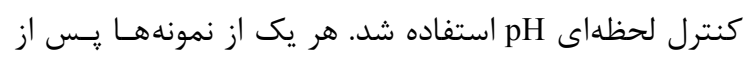

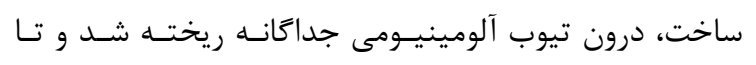

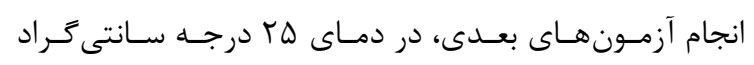

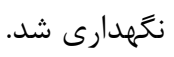

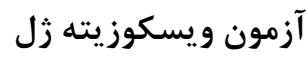

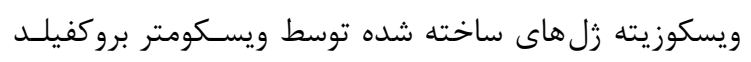

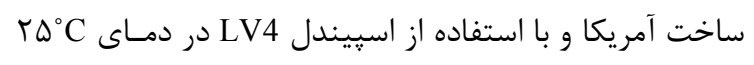

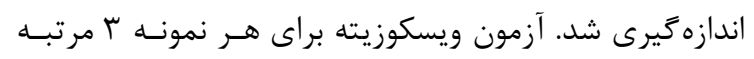

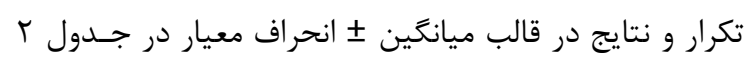
كزارش شده است.

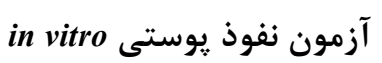

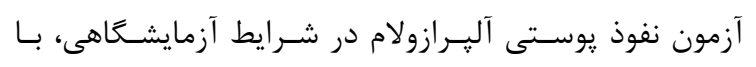

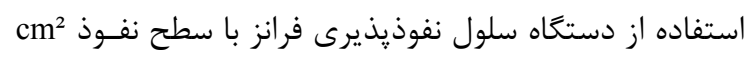
انجام شد. غشاى شبيه ساز يوست انسـان (Strat-MV

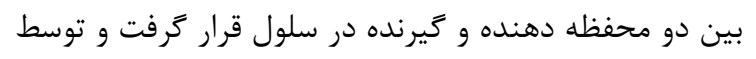

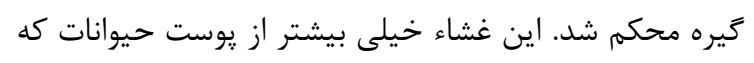

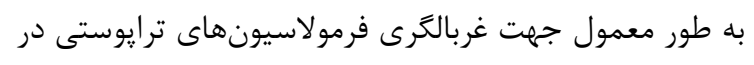

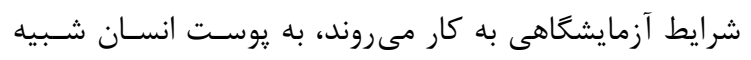

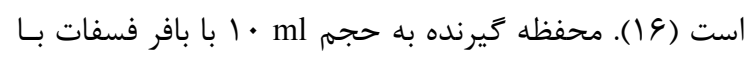

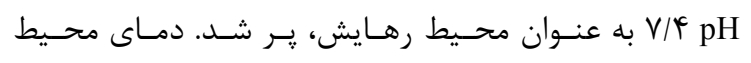

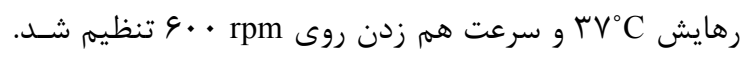

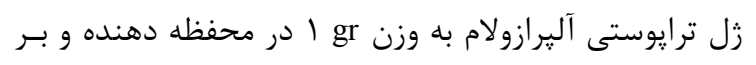

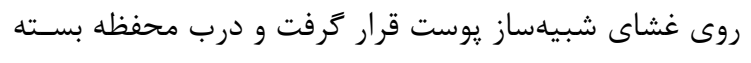

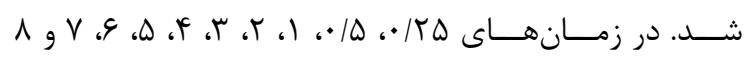

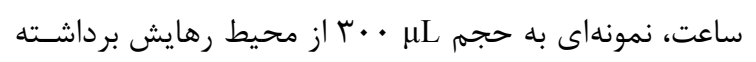

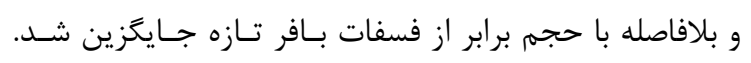

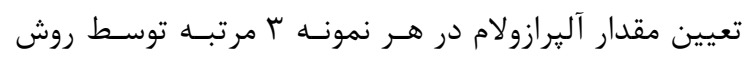
آمبام HPLC

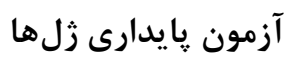

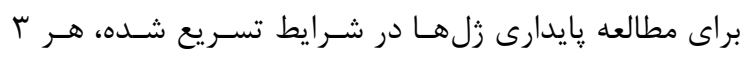

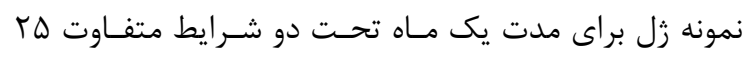

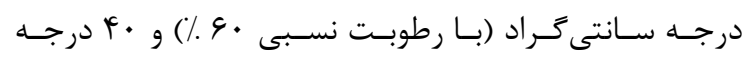

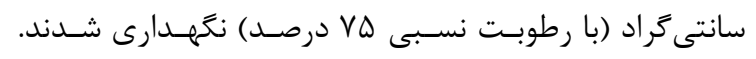

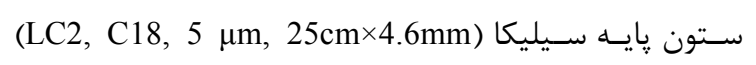

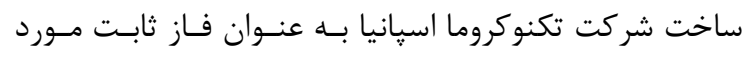

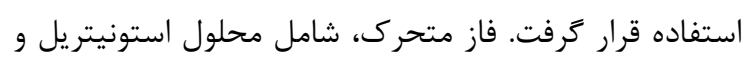

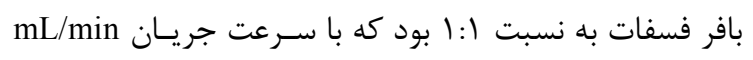

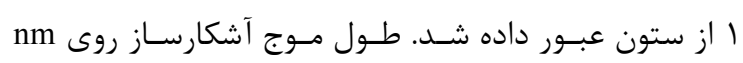

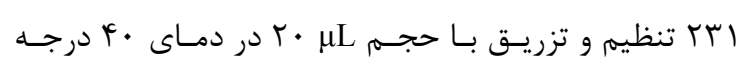

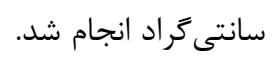

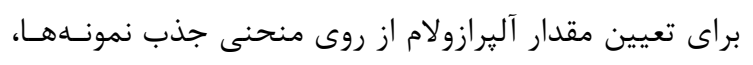

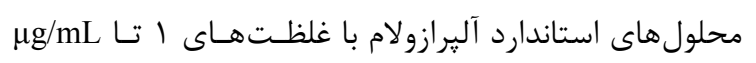

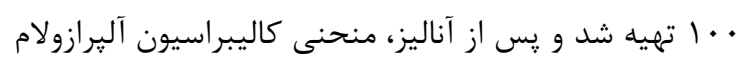

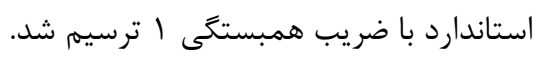

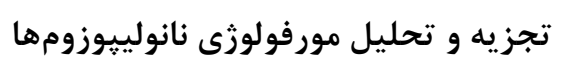

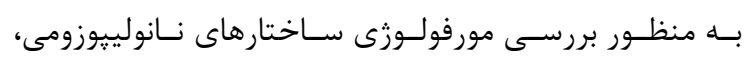

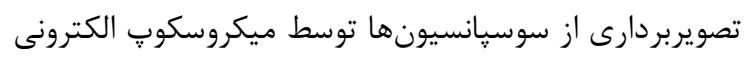

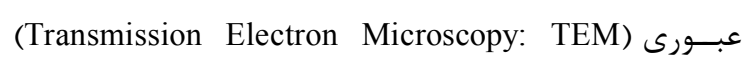
ساخت شركت كارل زايس آلمان انجـام شــــ مشهمود بـودن

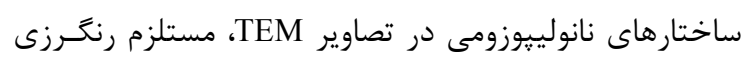

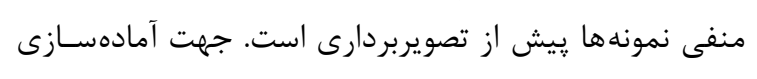

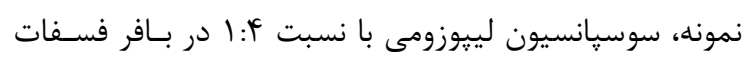

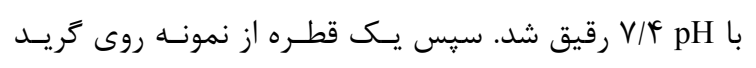

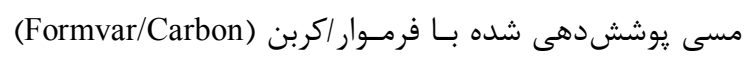

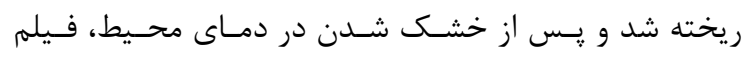

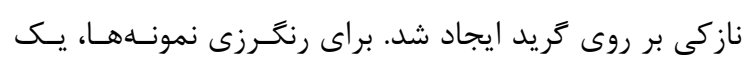

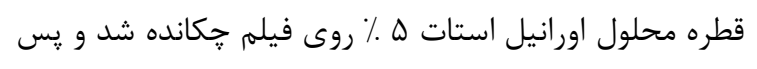

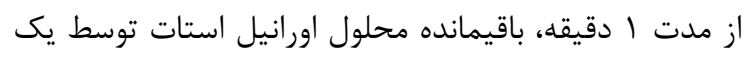

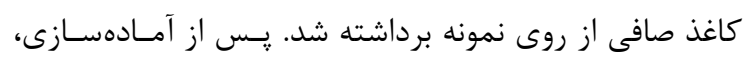

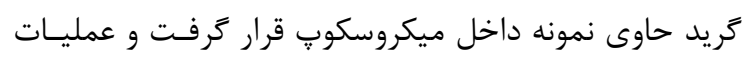

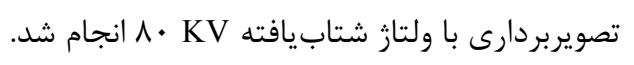
ساخت زل ترايوستى آلِرازولام

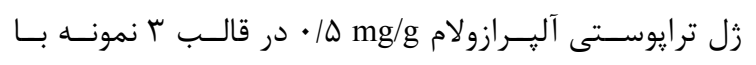

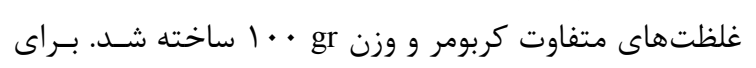

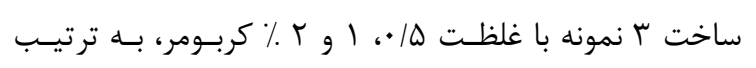

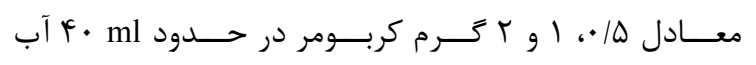

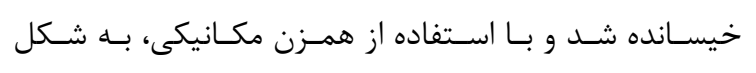

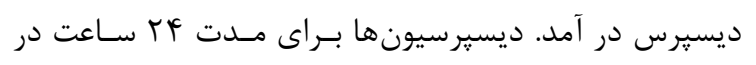

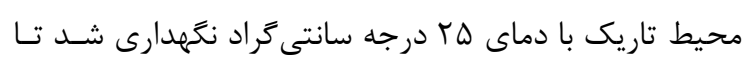

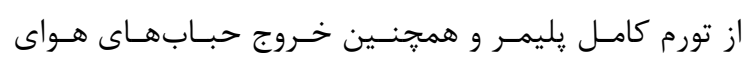

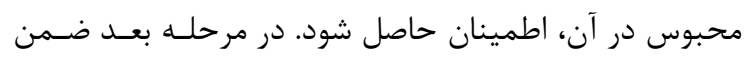

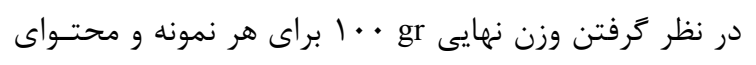

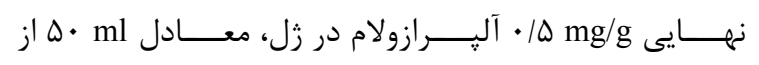


دليل تشكيل خودبه خودى ليِيوزومها حالت كِدِر و شيرى رنگ ييدا كرد. بر اساس نظريه قطعات مسطح دولايه (Bilayer) ته نشين شدن فسفوليييد محلول (planar fragments: BPFs در اتانول، در مرز بين فاز آبى/ حلال آلى، منجر به تشكيل قطعات مسطح دولايه (BPFs) شد و خودآرايى اين قطعات مسطح دو لايه، باعث تشكيل وزيكولها شد (IV).

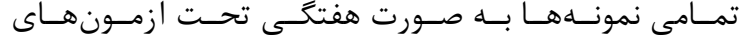
ويسكوزيته، تعيين مقدار دارو و جذب يوسـتى in vitro قـرار كرفتند.

\section{يافتهها}

تشكيل ساختارهاى ليبوزومىى

همزمان با شروع تزريق در فرايند تزريق حلال، فاز آبى به لـارئ

جدول ا. ماتريس طرح مركب مركزى: مقادير فاكتورها در هر فرمولاسيون ساخت نانولييوزوم و دادههاى ياسخ حاصل از آزمونها

\begin{tabular}{|c|c|c|c|c|}
\hline \multicolumn{2}{|c|}{ ياسخها (متغيرهاى وابسته) } & \multicolumn{2}{|c|}{ فاكتورها (متغيرهاى مستقل) } & \multirow{2}{*}{ فرمولاسيون } \\
\hline بازده محصورسازى (\%) & اندازه وزيكول (nm) & محتواى كلسترول (w/w \%) & غلظت فسفوليييد (mg/mL) & \\
\hline$V F / G \pm 1 / f$ & $q \vee / r \pm 1 / 0$ & 4 & $\Delta / \wedge \varphi$ & Ll \\
\hline$\wedge \mathrm{Q} / 9 \pm 1 / \vee$ & $1 r \Delta / 9 \pm r / 9$ & 4 & r. & Lr \\
\hline$v \cdot / r \pm \cdot / 9$ & $|f| / q \pm r / r$ & $\cdot / \mu r$ & $r \cdot$ & Lr \\
\hline $1 F / 9 \pm 1 / 9$ & $|r \varepsilon| \cdot \pm r / q$ & 4 & r. & Lf \\
\hline $99 / 9 \pm r / V$ & $|\varphi \varepsilon| \Lambda \pm r / \mid$ & $11 / 94$ & r. & $\mathrm{L} \omega$ \\
\hline $9 V / V \pm r / 9$ & $\mid V q / r \pm r / \Delta$ & $1 \cdot$ & $r$. & Ls \\
\hline $9 / / \Lambda \pm r / 4$ & $\mid \wedge \varepsilon / 0 \pm 9 / 4$ & 4 & $r F / l f$ & LV \\
\hline $91 / 1 \pm r / 1$ & $119 / \pi \pm 1 / 1$ & $1 \cdot$ & 1. & $\mathrm{~L} \wedge$ \\
\hline$\Lambda \cdot / 0 \pm 1 / r$ & $\mid V F / r \pm r / \Lambda$ & r & $r$. & L9 \\
\hline$\Lambda \Delta / \Gamma \pm 1 / 9$ & $|r| / 1 \pm 1 / 9$ & 4 & $r$. & Ll. \\
\hline $9 \Delta / 9 \pm 1 / \cdot$ & $11 \cdot / 4 \pm 1 / V$ & r & $1 \cdot$ & L11 \\
\hline$\Lambda \Delta / 1 \pm 1 / \mu$ & $\mid r r / \Lambda \pm r / \cdot$ & 4 & $r$. & Lir \\
\hline$\Lambda F / \pi \pm 1 / \Delta$ & $1 r q / 1 \pm r / V$ & 4 & $r \cdot$ & Lir \\
\hline
\end{tabular}

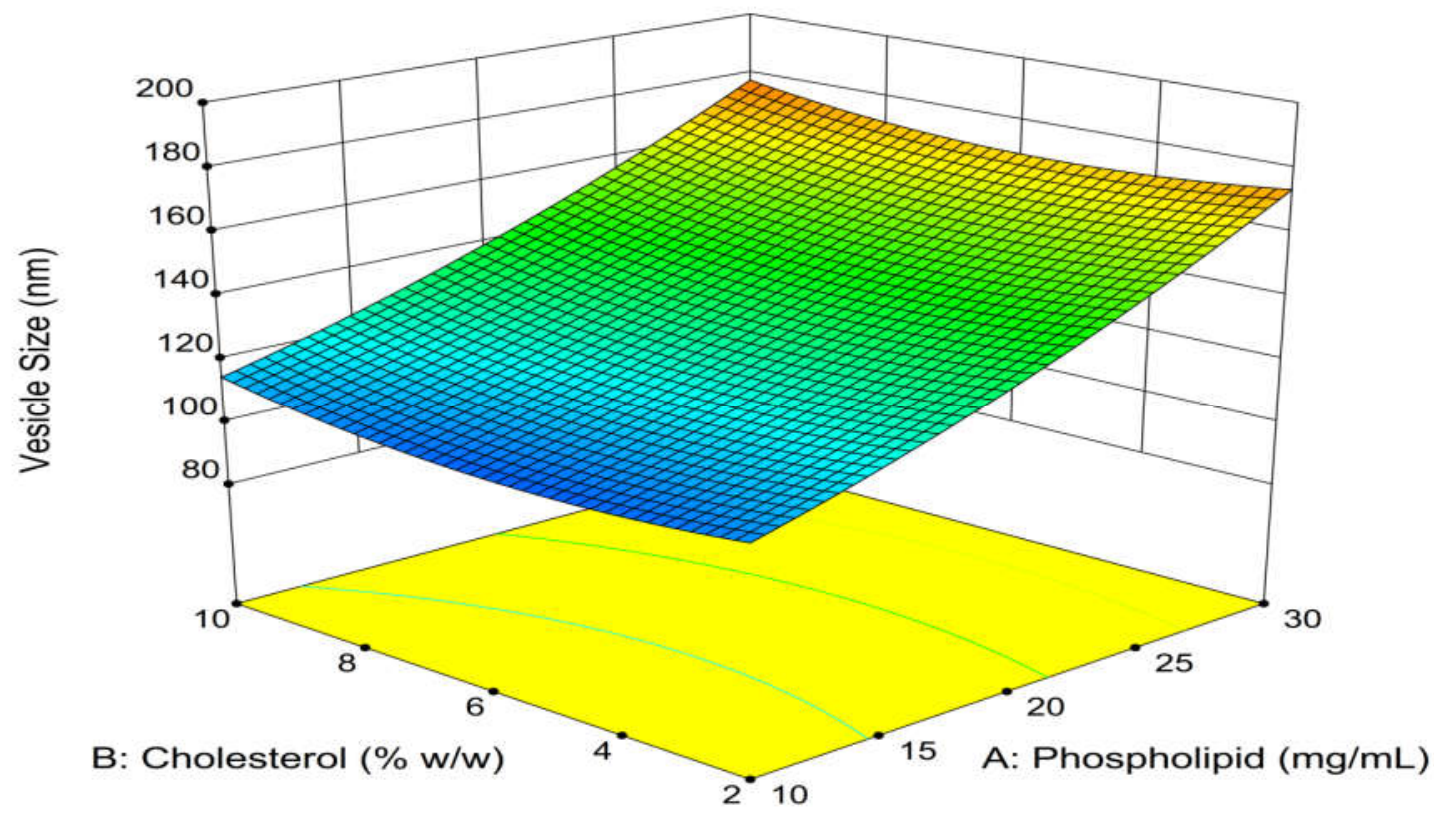

شكل ا. دياگرام سطح پاسخ تاثير فاكتورها بر اندازه وزيكول 
مشاهده نشد. وزيكولهاى تكلايه كوجى (SUVs) با اندازه

•ه تا • • ا نانومتر به وضوح در تصوير قابل مشاهده هستند.

مطالعه ويسكوزيته

ويسكوزيته زلهاى ساخته شده، در جدول r كزارش شده است. هر ץ نمونه زل، از ويسكوزيته مناسب براى اين شكل دارويى برخوردارند.

in vitro مطالعه جذب :بوستى

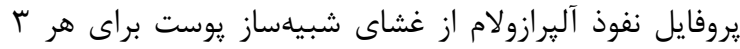

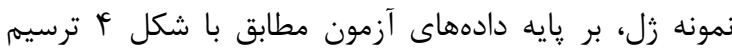

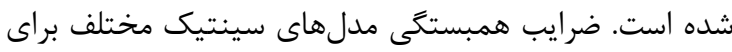
نفوذ آليرازولام از غشاء، مطابق با جدول r محاسبه شد.

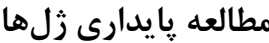

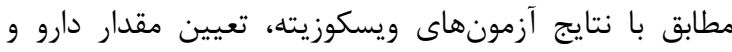
جذب يوستى in vitro طى مدت يك ماه و به صورت هفتتى أنى

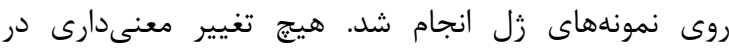
خصوصيات زلها طى اين مدت ايجاد نشد.

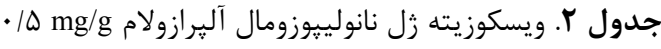

\begin{tabular}{|c|c|c|}
\hline ويسكوزيته (mPa.s) & محتواى كربومر (/w/w/w) & فرمولاسيون زل \\
\hline MF.TIQ & $\cdot / \Delta$ & G) \\
\hline$\Delta \Lambda . V T F$ & 1 & Gr \\
\hline 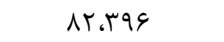 & $r$ & $\mathrm{Gr}^{\mathrm{r}}$ \\
\hline
\end{tabular}

بحث

طى سالهاى اخير تحقيقات متعددى جهت فرمولاسيون

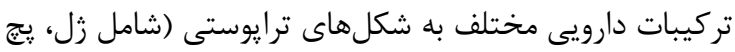

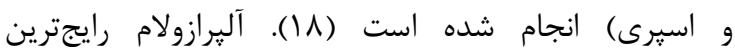
بنزوديازيين براى درمان اختلالهاى هراسى است (•) (·).

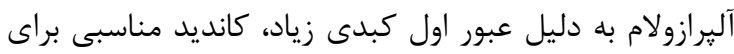

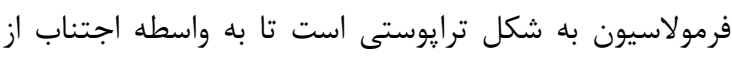

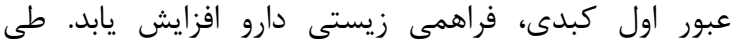

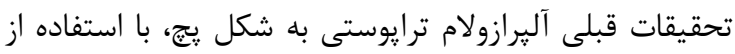

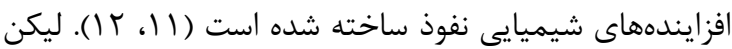
با توجه به سهولت مصرف زل و يذيرش بهتر آن از سوى

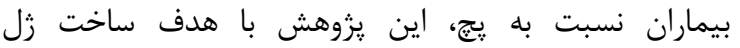

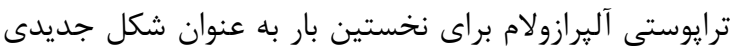

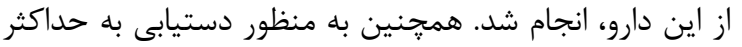

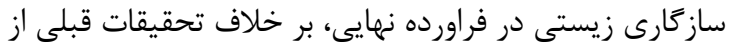

توسعه مدلهاى آمارى

تحليل ركرسيون دادهاى اندازه وزيكول و بازده محصورسازى، آناري،

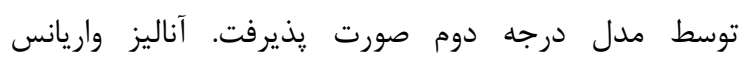
بر روى هر يك از دو رياسخ انجام شد. ضريب (ANOVA)

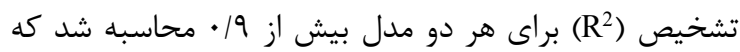

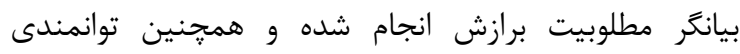

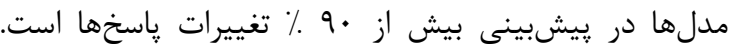

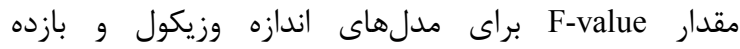

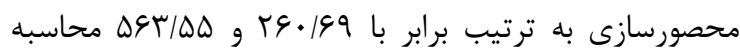

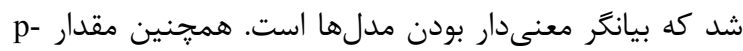
value

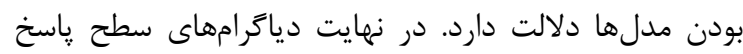

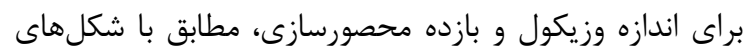

$$
\text { أو بر ترسيم شد. }
$$

تاثير فاكتورها بر اندازه وزيكول

شكل 1 بيانكر تاثير فاكتورهاى مورد بررسى برازه وزيكول اندازه وزيكول است. با افزايش غلظت فسفوليييد در فرمولاسيون، رشد قابل

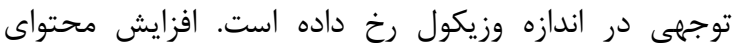

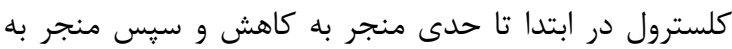
افزايش اندازه وزيكول ها شدر.

$$
\text { تاثير فاكتورها بر بازده محصورسازى وزيك }
$$

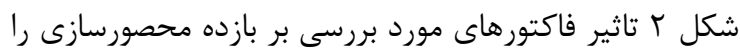

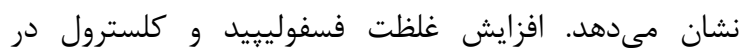
فرمولاسيون، منجر به افزايش بازده محصورسازى شد. بهينهسازى اندازه وزيكول و بازده محصور سازى

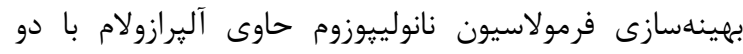

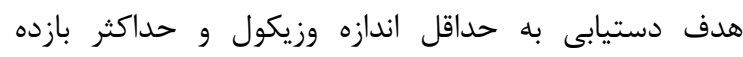
محصورسازى، توسط نرمافزار مesign-Expert انجام شد.

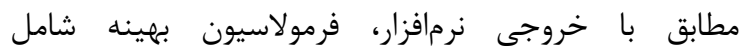

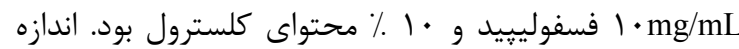
وزيكول و بازده محصورسازى براى لييوزومهاى تهيه شده با

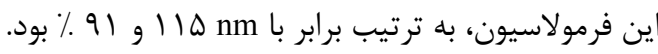

\section{بر رسى خصوصيات مورفولوزى نانولييوزوم} طى مطالعه مورفولوزى فرمولاسيون بهينه توسط ميكروسكوب الكترونى عبورى، نانولييوزومهاى كروى شكل مشاهده شدند

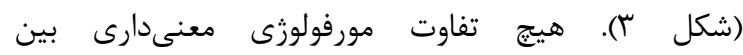

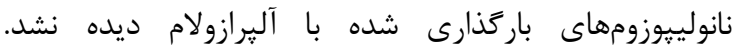
همجنين در هيج يك از تصاوير ميكروسكويى، بلور آليرازولام 

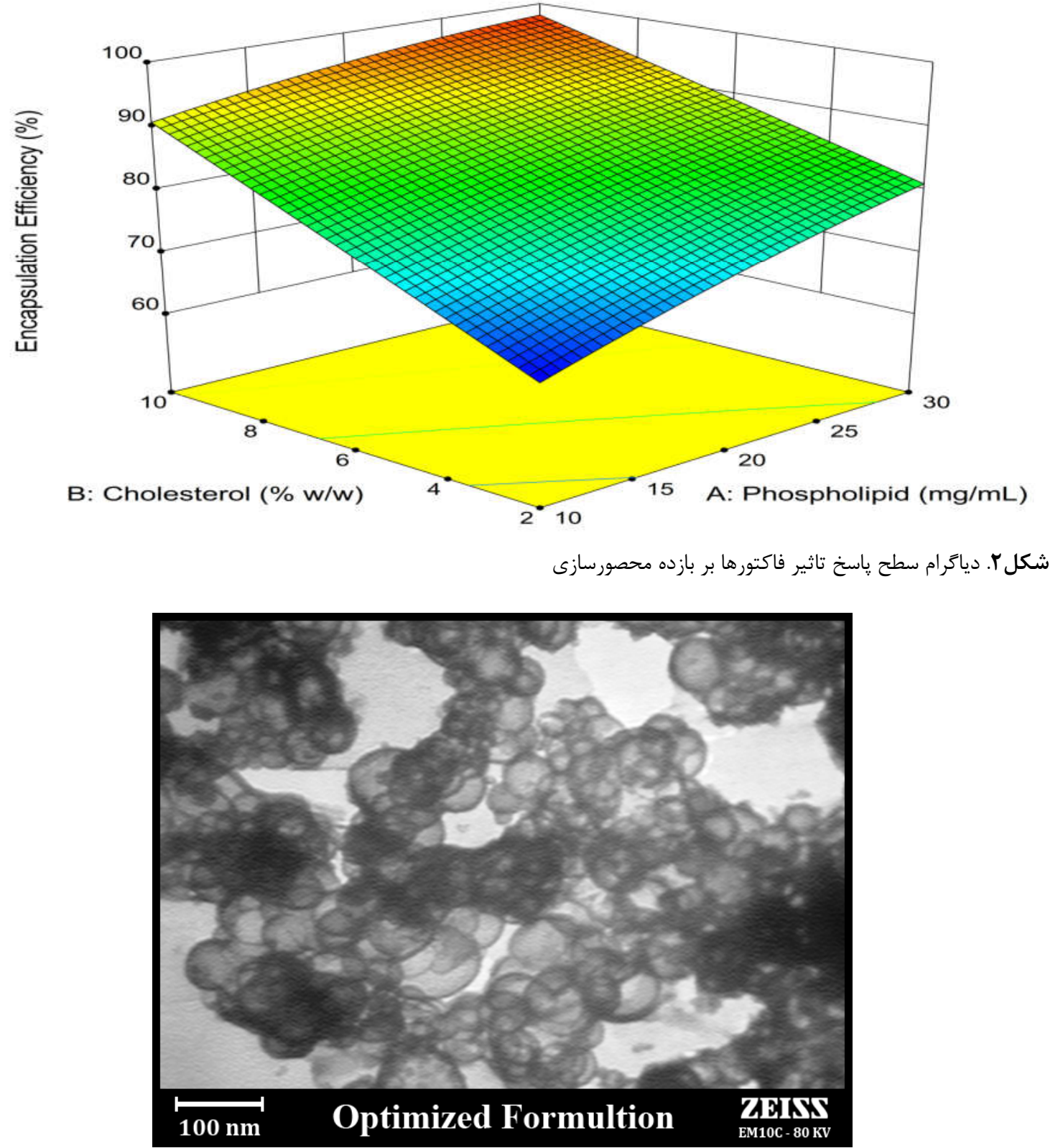

شكل rr. تصوير ميكروسكوب الكترونى عبورى (TEM) از فرمولاسيون بهينه نانولييوزوم حاوى آلبرازولام

شدن سطوح ليبيدى و همجنين افزايش وزيكولهاى تكلايه

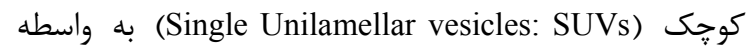
افزايش غلظت فسفوليييد بوده كه در نهايت منجر به تشكيل

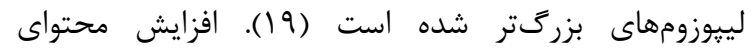

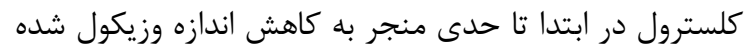

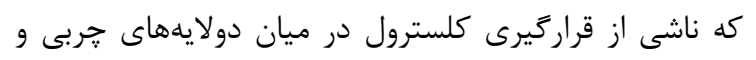

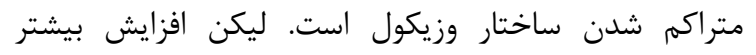

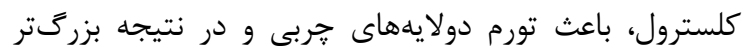
شدن اندازه وزيكول ها شده است (· (T).
نانولييوزومها به عنوان جايكزين افزايندههاى شيميايى نفوذ،

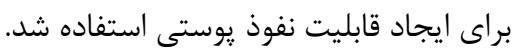

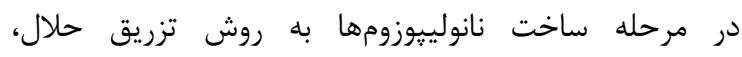

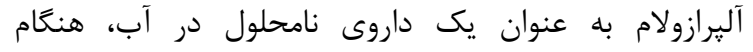

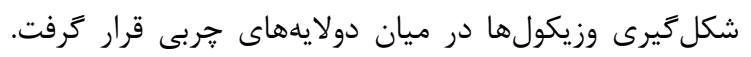

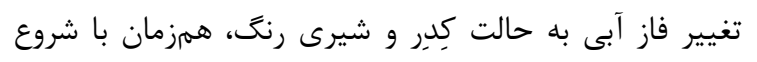

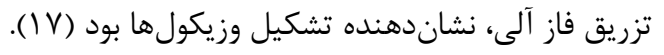

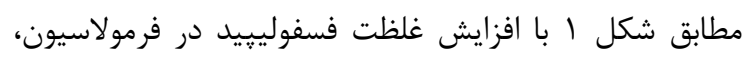

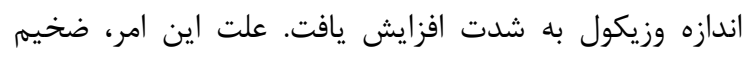




\begin{tabular}{|c|c|c|c|c|c|c|c|}
\hline \multicolumn{2}{|c|}{ مدل هيكوجى } & \multicolumn{2}{|c|}{ مدل درجه يك } & \multicolumn{2}{|c|}{ مدل درجه صفر } & \multirow{2}{*}{ 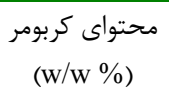 } & \multirow[t]{2}{*}{ نمونه زل } \\
\hline $\mathrm{R}^{2}$ & $\mathrm{~K}^{*}$ & $\mathrm{R}^{2}$ & $\mathrm{~K}^{*}$ & $\mathrm{R}^{2}$ & $\mathrm{~K}^{*}$ & & \\
\hline$\cdot \mid \Lambda \wedge \vee \Delta$ & $r \Delta / \cdot r V$. & $\cdot \mid \Delta \wedge \Delta Q$ & •/194. & - NkqR & 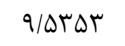 & $\cdot 10$ & G) \\
\hline •/9rv. & rV/GYA. & $\cdot 190 \cdot r$ & - Irtrq & - IATIA & $1 \cdot / 4 F \Delta$. & 1 & Gr \\
\hline • & $r q / f \mid V$. & $\cdot / V H I I$ & $\cdot|r| \cdot f$ &.$/ 91 \wedge F$ & 11/rAk. & r & Gr \\
\hline
\end{tabular}

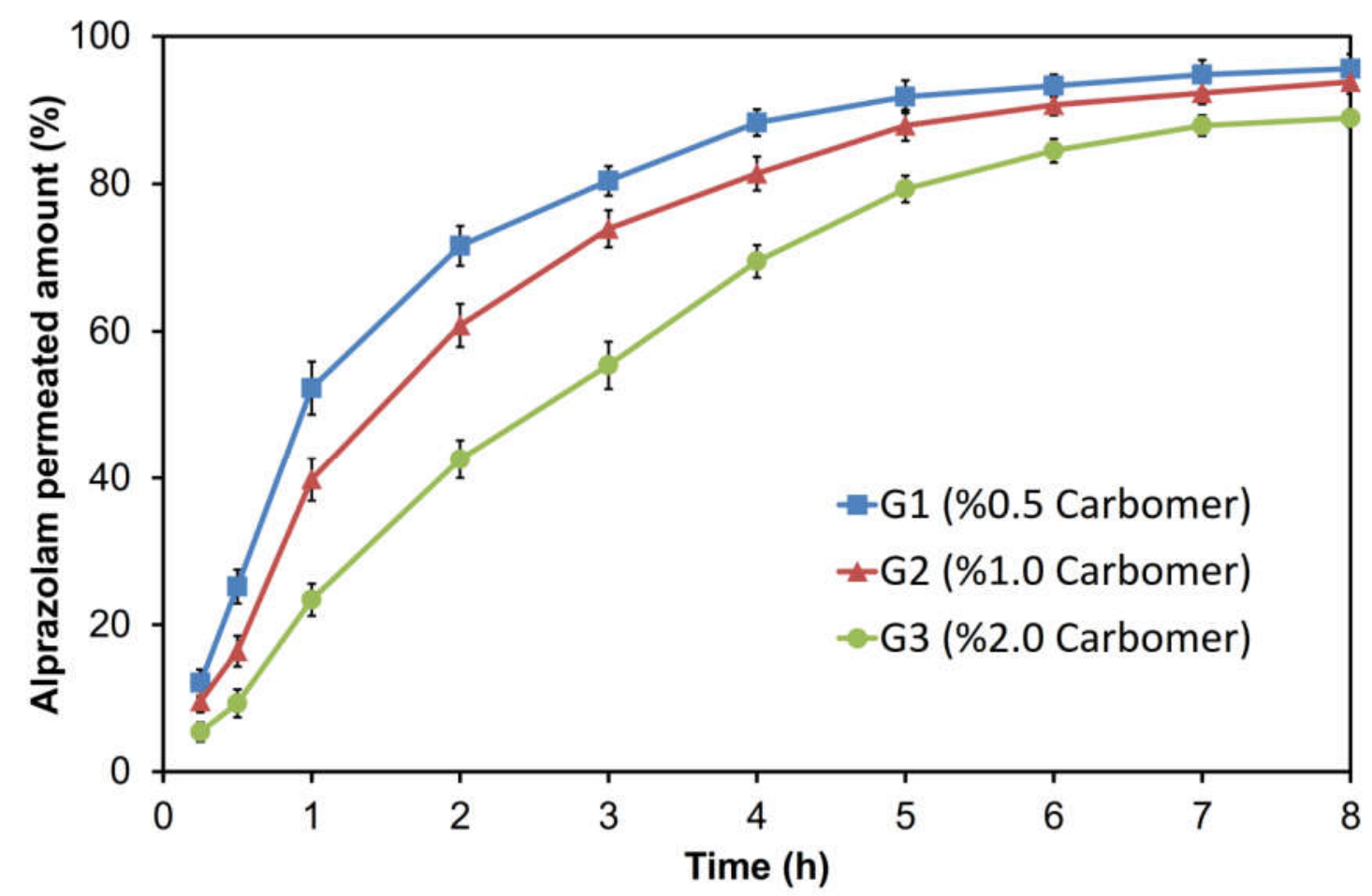

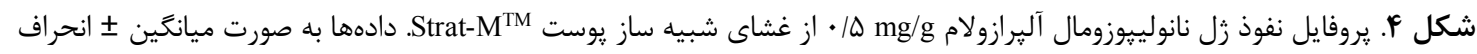

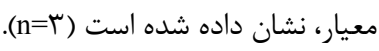

فرمولاسيون بهينه، به ترتيب برابر با

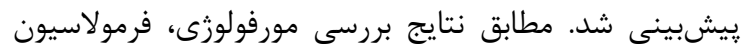

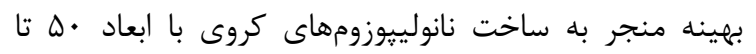

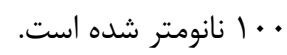

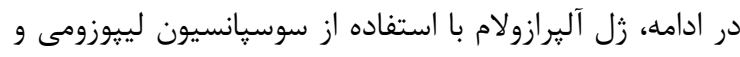

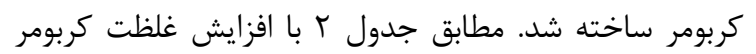

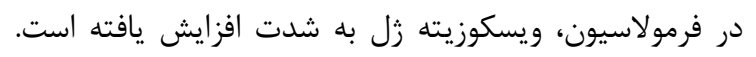

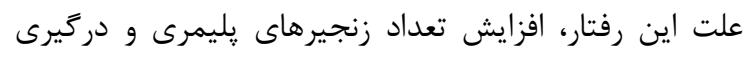
بيشتر بين آنها در اثر افزايش مقدار كربومر بوده كه در نهر نهايت منجر به افزايش ويسكوزيته زل شل شده است.

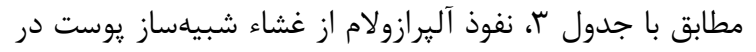

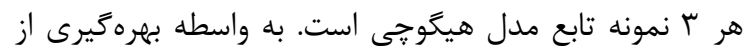

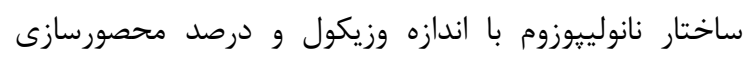
مناسب در ساخت زلها، هر ب نمونه به سطح مطلوبى از نفوذ وزي
مطابق شكل r با افزايش غلظت فسفوليييد در فرمولاسيون،

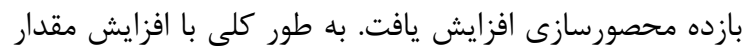

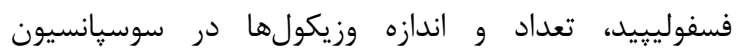
لييوزومى افزايش يافته كه در مجموع ظرفيت بيشترى داد را براى فيكاي

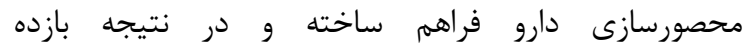

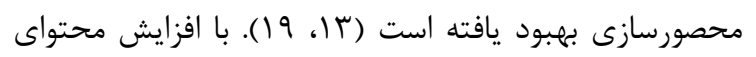

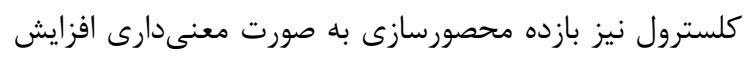

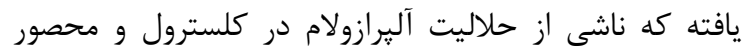

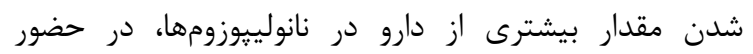

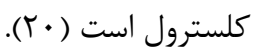
با بهينهاسازى مدلهاى آمارى توسعه يافته براى اندازه وزيكول

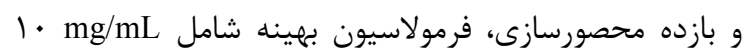

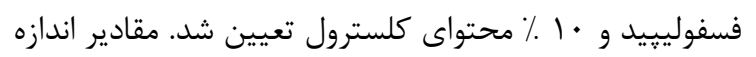

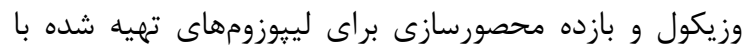




$$
\begin{aligned}
& \text { است. اين در حالى است كه تحقيقات قبلى در خصوص ساخت }
\end{aligned}
$$

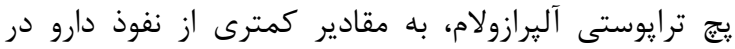

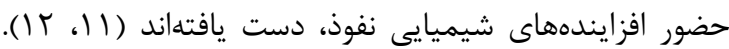

$$
\begin{aligned}
& \text { بنابراين زل ترايوستى آليرازولام با موفقيت در اين يزوهش نائن }
\end{aligned}
$$

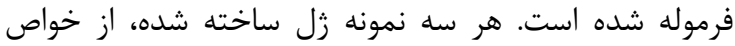

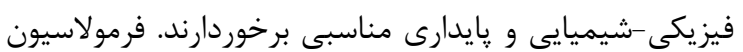

$$
\begin{aligned}
& \text { زل Gr به دليل دركيرى بيشتر لييوزومها درون زنجيرهاى }
\end{aligned}
$$

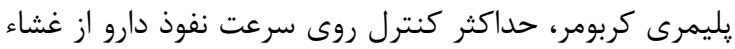

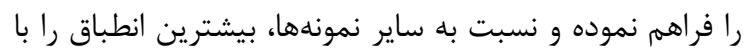

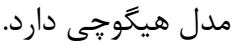

\section{تقدير و تشكر}

اين مقاله حاصل بخشى از نتايج رساله آقاى سيدحسام الدين هاشمى براى دريافت درجه دكترى تخصصى در در رشته

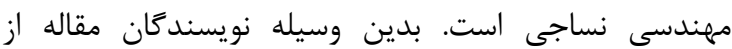
شركتهاى داروسازى يارس دارو، سبحان و Lipoid GmbH

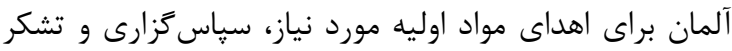

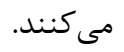

يوستى دست يافتهاند. به نحوى كه بيش از •9 ٪ آليرازولام

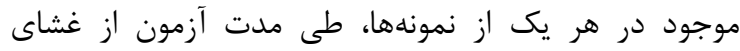

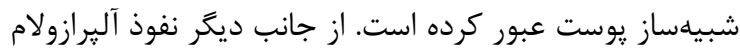
از غشاء، به صورت بِيوسته و كنترل شده صورت كرفته است.

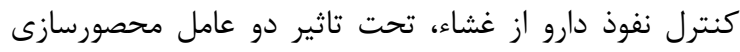

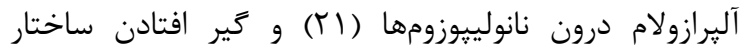
نانولييوزوم بين زنجيرهاى يليمرى كربومر (Tr)، حاصل شده

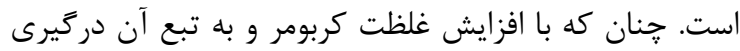

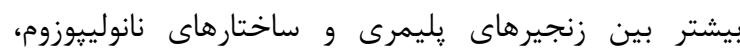
سرعت نفوذ دارو از غشاء كاهش يافته است. بنابراين با كنترل

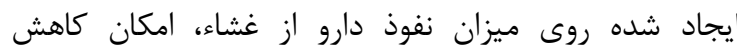
نوسانات غلظت دارو نيز فراهم شد. عدم تغيير خصوصيات زلها (شامل ويسكوزيته، محتواى دارو و جذب يوستى) طى مدت يك ماهه نتحهدارى در شرايط تسريع شده، بيانكر קايدارى مطلوب زلهاب مانى ساخته شده است. در يايان مىتوان نتيجه كرفت كه زلهاي تهائ تهيه شده به واسطه

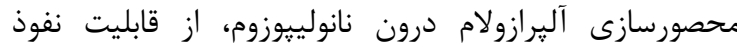

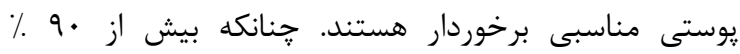
آليرازولام موجود در زل از غشاء شبيهساز يوست، عبور كرده

\section{REFERENCES}

1. Kaur R, Ajitha M. Transdermal delivery of fluvastatin loaded nanoemulsion gel: Preparation, characterization and in vivo anti-osteoporosis activity. Eur J Pharm Sci 2019; 136:1-10.

2. Ahad A, Aqil M, Ali A. Investigation of antihypertensive activity of carbopol valsartan transdermal gel containing 1, 8-cineole. Int J Biol Macromol 2014; 64: 144-9.

3. Ita KB. Chemical Penetration Enhancers for Transdermal Drug Delivery - Success and Challenges. Curr Drug Deliv 2015; 12: 645-51

4. Chen Y, Quan P, Liu X, Wang M, Fang L. Novel chemical permeation enhancers for transdermal drug delivery. Asian J Pharm Sci 2014; 9: 51-64.

5. Londhe VY, Bhasin B. Transdermal lipid vesicular delivery of iloperidone: Formulation, in vitro and in vivo evaluation. Colloids Surf B Biointerfaces 2019; 183: 1-7.

6. Brown GG, Ostrowitzki S, Stein MB, von Kienlin M, Liu TT, Simmons A, et al. Temporal profile of brain response to alprazolam in patients with generalized anxiety disorder. Psychiatry Res 2015; 233: 394-401

7. Isbister GK, O'Regan L, Sibbritt D, Whyte IM. Alprazolam is relatively more toxic than other benzodiazepines in overdose. Br J Clin Pharmacol 2004; 58: 88-95.

8. Deacon RM, Nielsen S, Leung S, Rivas G, Cubitt T, Monds LA, et al. Alprazolam use and related harm among opioid substitution treatment clients - 12 months follow up after regulatory rescheduling. Int J Drug Policy 2016; 36: 104-11.

9. Chen TT, Ko CH, Chen ST, Yen CN, Su PW, Hwang TJ, et al. Severity of alprazolam dependence and associated features among long-term alprazolam users from psychiatric outpatient clinics in Taiwan. J Formos Med Assoc 2015; 114: 1097-104.

10. Jafariazar Z, Sadjady SK, Chamani N, Afshar M. Formulation and in vitro evaluation of orally disintegrating film of alprazolam. Med Sci J Islamic Azad Univ 2019; 29: 117-24. [In Persian]

11. Soler LI, Boix A, Lauroba J, Colom H, Domenech J. Transdermal delivery of alprazolam from a monolithic patch: formulation based on in vitro characterization. Drug Dev Ind Pharm 2012; 38: 1171-8. 
12. Maji P, Gandhi A, Jana S, Maji N. Preparation and characterization of maleic anhydride cross-linked chitosanpolyvinyl alcohol hydrogel matrix transdermal patch. J Pharma Sci Tech 2013; 2: 62-67.

13. Jaafar-Maalej C, Diab R, Andrieu V, Elaissari A, Fessi H. Ethanol injection method for hydrophilic and lipophilic drug-loaded liposome preparation. J Liposome Res 2010; 20: 228-43.

14. Ge Y, Ge M. Development of tea tree oil-loaded liposomal formulation using response surface methodology. J Liposome Res 2015; 25: 222-31.

15. Lopez-Pinto JM, González-Rodríguez ML, Rabasco AM. Effect of cholesterol and ethanol on dermal delivery from DPPC liposomes. Int J Pharm 2005; 298: 1-12.

16. Haq A, Goodyear B, Ameen D, Joshi V, Michniak-Kohn B. Strat-M ${ }^{\circledR}$ synthetic membrane: Permeability comparison to human cadaver skin. Int J Pharm 2018; 547: $432-7$.

17. Lasic DD. The mechanism of vesicle formation. Biochem J 1988; 256: 1-11.

18. Shingade GM, Aamer Q, Sabale PM, Grampurohit ND, Gadhave MV, Jadhav SL, et al . Review on: Recent trend on transdermal drug delivery system. J Drug Deliv Ther 2012; 2: 66-75.

19. Sezer AD, Akbuğa J, Baş AL. In vitro evaluation of enrofloxacin-loaded MLV liposomes. Drug Deliv 2007; 14: 4753.

20. Briuglia ML, Rotella C, McFarlane A, Lamprou DA. Influence of cholesterol on liposome stability and on in vitro drug release. Drug Deliv Transl Res 2015; 5: 231-42.

21. Sacha M, Faucon L, Hamon E, Ly I, Haltner-Ukomadu E. Ex vivo transdermal absorption of a liposome formulation of diclofenac. Biomed Pharmacother 2019; 111: 785-90.

22. Zhang Y, Ng W, Hu J, Mussa SS, Ge Y, Xu H. Formulation and in vitro stability evaluation of ethosomal carbomer hydrogel for transdermal vaccine delivery. Colloids Surf B Biointerfaces 2018; 163: 184-91. 